\section{TRANSMISIÓN VERTICAL DEL VIRUS DEL DENGUE EN EL Aedes aegypti, PERÚ}

\author{
VERTICAL TRANSMISSION OF DENGUE VIRUS \\ IN Aedes aegypti, PERU
}

\begin{abstract}
César Cabezas ${ }^{1,2, a}$, María Paquita García ${ }^{1, b}$, Jorge Valle ${ }^{1, c}$, Pamela Yañez ${ }^{1, c}$, Luis Fachin ${ }^{3, d}$, Carmen Sinti ${ }^{1, c}$, Enrique Mamani ${ }^{1, c}$
\end{abstract}

Sr. Editor. El Aedes aegypti cumple una función importante en la transmisión del virus del dengue en poblaciones humanas, particularmente en zonas tropicales y subtropicales del mundo. El mantenimiento de la circulación viral en la naturaleza en los periodos interepidémicos es un fenómeno estudiado en otros medios ${ }^{(1,2)}$, pero poco en el nuestro como en la Amazonía; por lo que se realizó un estudio para determinar la transmisión vertical del virus en el Aedes aegypti en localidades de la región Ucayali donde es persistente la presencia de brotes de dengue.

Entre febrero y marzo de 2012 se colectaron muestras de huevos, larvas y pupas del vector $A$. aegypti, en zonas de brote de dengue en las localidades de tres distritos de Pucallpa. En total se colectaron 50 larvas y pupas (LP) en cada lugar. La colecta se hizo cumpliendo con las normas y medidas de protección personal que son las habituales para la vigilancia y control vectorial que se realiza en las diferentes regiones del país. Las muestras colectadas fueron enviadas al Laboratorio de Entomología del Instituto Nacional de Salud (INS) en Lima, donde se efectuó la crianza de LP hasta el estadio adulto del $A$. aegypti y su clasificación en mosquitos machos y hembras.

En el Laboratorio de Metaxénicas Virales del INS, se determinó la presencia de ARN viral, mediante la prueba de RT-PCR en tiempo real en LP y RT-PCR en tiempo real en adultos (machos y hembras) ${ }^{(3,4)}$. Antes de aplicar la prueba se hicieron pools de LP y de adultos conformados por 2-10 unidades de cada lugar colectado. Los resultados

\footnotetext{
1 Centro Nacional de Laboratorios de Salud Pública. Instituto Nacional de Salud. Lima, Perú

2 Instituto de Medicina Tropical Daniel A. Carrión, Facultad de Medicina, Universidad Nacional Mayor de San Marcos. Lima, Perú

3 Laboratorio de Referencia, Dirección Regional de Salud de Ucayali. Ucayali, Perú

a Médico infectólogo; ${ }^{\mathrm{b}}$ tecnólogo médico; ${ }^{\mathrm{c}}$ biólogo; ${ }^{\mathrm{d}}$ técnico en entomología

Recibido: 03-12-14 Aprobado: 10-12-14
}

Citar como: Cabezas C, García MP, Valle J, Yañez P, Fachin L, Sinti C, et al. Transmisión vertical del virus del dengue en el Aedes aegypti, Perú [carta] Rev Peru Med Exp Salud Publica. 2015;32(1):191-2.
Tabla 1. Presencia de RNA del virus del dengue serotipo 2 en larvas, pupas y adultos del Aedes aegypti, según sectores distritales

\begin{tabular}{|c|c|c|c|c|c|}
\hline \multirow{3}{*}{ Distrito } & \multirow{3}{*}{ Localidad } & \multicolumn{2}{|c|}{ Estadio } & \multirow{2}{*}{$\frac{\text { Larvas }}{\text { RT-PCR }}$} & \multirow{2}{*}{$\begin{array}{l}\text { Adultos } \\
\text { RT-PCR }\end{array}$} \\
\hline & & Larvas & Adultos & & \\
\hline & & III - IV & machos & dengue & dengue \\
\hline Yarinacocha & Nuevo Paraíso & 10 & 5 & $\mathrm{~N}$ & $\mathrm{~N}$ \\
\hline Yarinacocha & Electroucayali & 10 & 5 & $\mathrm{~N}$ & $\mathrm{~N}$ \\
\hline Yarinacocha & $\begin{array}{l}\text { Hospital } \\
\text { Amazónico }\end{array}$ & 10 & 5 & $\mathrm{~N}$ & DENV-2 \\
\hline Yarinacocha & DESA-LSP & 10 & 5 & $\mathrm{~N}$ & DENV-2 \\
\hline Yarinacocha & $\begin{array}{l}\text { Shimbaray } \\
\text { (aeropuerto) }\end{array}$ & 10 & 5 & $\mathrm{~N}$ & DENV-2 \\
\hline Calleria & Nuevo Paraíso & 10 & 5 & $\mathrm{~N}$ & DENV-2 \\
\hline Calleria & 9 de Octubre & 10 & 5 & $\mathrm{~N}$ & DENV-2 \\
\hline Calleria & Bellavista & 10 & 0 & $\mathrm{~N}$ & 0 \\
\hline Manantay & San Fernando & 10 & 5 & $\mathrm{~N}$ & DENV-2 \\
\hline Manantay & Manantay & 20 & 5 & $\mathrm{~N}$ & $\mathrm{~N}$ \\
\hline
\end{tabular}

$\mathrm{N}$ : negativo; DENV-2: virus dengue serotipo 2

se muestran en la Tabla 1, donde se observa que en muestras de adultos se logró determinar la presencia de RNA del virus dengue serotipo 2 (DENV-2) en mosquitos adultos hembras, en 6 de las 10 localidades estudiadas.

Este estudio ha permitido determinar la presencia de DENV-2 a partir de mosquitos $A$. aegypti criados en laboratorio, lo cual indicaría la ocurrencia de transmisión transovárica en este vector, que por primera vez se describe en nuestro medio. Esta forma de transmisión podría explicar la persistencia de casos de dengue en las áreas estudiadas. La determinación de la presencia del virus del dengue en el $A$. aegyptien estadio larvario, podría servir como un indicador de alto riesgo para reorientar la vigilancia vectorial y permitir medidas de prevención y control vectorial más adecuadas y oportunas.

Conflictos de interés: los autores declaran no tener conflictos de interés.

Fuentes de financiamiento: Instituto Nacional de Salud.

\section{REFERENCIAS BIBLIOGRÁFICAS}

1. Martins VE, Alencar CH, Kamimura MT, de Carvalho Araújo FM, de Simone SG, Dutra RF, et al. Occurrence of natural vertical transmission of dengue-2 and dengue-3 viruses in Aedes aegypti and Aedes albopictus in Fortaleza, Ceará, Brazil. PLoS One. 2012;7(7):e41386. doi: 10.1371/ journal.pone.0041386.

2. Chen CF, Shu PY, Teng HJ, Su CL, Wu JW, Wang JH, et al. Screening of dengue virus in field-caught Aedes aegypti 
and Aedes albopictus (Diptera: Culicidae) by one-step SYBR green-based reverse transcriptase-polymerase chain reaction assay during 2004-2007 in Southern Taiwan. Vector Borne Zoonotic Dis. 2010 Dec;10(10):1017-25. doi: 10.1089/ vbz.2008.0069.

3. Martínez NE, Dzul-Manzanilla F, Gutiérrez-Castro C, Ibarra-López J, Bibiano-Marín W, López-Damián L, et al. Natural vertical transmission of dengue-1 virus in Aedes aegypti populations in Acapulco, Mexico. J Am Mosq Control Assoc. 2014 Jun;30(2):143-6.

4. Chien LJ, Liao TL, Shu PY, Huang JH, Gubler DJ, Chang GJ. Development of real-time reverse transcriptase PCR assays to detect and serotype dengue viruses. J Clin Microbiol. 2006 Apr;44(4):1295-304.

Correspondencia: César Cabezas Sánchez

Dirección: Av. Cápac Yupanqui 1400, Lima 11, Perú.

Teléfono: 998880403

Correo electrónico:ccabezas@ins.gob.pe

\section{CROWDFUNDING CIENTIIFICO: OTRA ALTERNATIVA DE FINANCIAMENTO PARA INVESTIGADORES JÓVENES EN PERÚ}

\section{SCIENTIFIC CROWDFUNDING: ALTERNATIVE FINANCING FOR YOUNG RESEARCHERS IN PERU}

Carlos A. Huayanay-Espinoza ${ }^{1,2, a}$, Julio A. Poterico ${ }^{3, b}$

Sr. Editor. La investigación en ciencia y tecnología (СуT) fortalece al capital social generando desarrollo y crecimiento económico sostenible de un país (1). En el Perú, se estima que el 2021 habrá una brecha de 17 mil investigadores en las especialidades de ingeniería y tecnología, ciencias naturales, ciencias médicas y ciencias agrícolas; contabilizándose 2555

\footnotetext{
1 Centro de Investigación para el Desarrollo Integral y Sostenible (CIDIS), Universidad Peruana Cayetano Heredia. Lima, Perú.

2 Escuela de Tecnología Médica, Facultad de Medicina "Alberto Hurtado", Universidad Peruana Cayetano Heredia. Lima, Perú.

3 Puesto de Salud Santa Cruz de Ratacocha, Ministerio de Salud. Huánuco, Perú.

a Licenciado en Tecnología Médica, ${ }^{\mathrm{b}}$ médico cirujano Recibido: 17-11-14 Aprobado: 19-11-14
}

Citar como: Huayanay-Espinoza CA, Poterico JA. Crowdfunding científico: otra alternativa de financiamento para investigadores jóvenes en Perú [carta]. Rev Peru Med Exp Salud Publica. 2015;32(1):192-3. investigadores en el área de ciencias médicas y de la salud (2). Recientemente, por medio del Consejo Nacional de Ciencia, Tecnología e Innovación Tecnológica (CONCYTEC) se están implementando estrategias para cerrar esta brecha de investigadores y, al mismo tiempo, fortalecer y promover el desarrollo de la investigación mediante financiamiento académico y transferencias de recursos ${ }^{(2)}$.

En los próximos años, con el aumento de investigadores se incrementará también la necesidad de explorar y concretar otras alternativas de financiamiento; sobre todo para investigadores jóvenes, las cuales podrían surgir de instituciones académicas como las universidades o desde la misma sociedad. Así por ejemplo, ha surgido el crowfunding (micromecenazgo), un movimiento que consiste en captar el aporte económico de un grupo de personas o instituciones en forma de donaciones para financiar proyectos de interés que contribuyan y aceleren la búsqueda de conocimiento y soluciones a los problemas cotidianos de diversas áreas. Los aportantes deciden los temas prioritarios, tipo de proyectos e investigadores para llevarlos a cabo, generando mayor oportunidad para jóvenes con ideas y/o proyectos innovadores y muchas veces audaces.

La aplicación de este financiamiento ha tenido resultados positivos para las nuevas cohortes de investigadores en Europa y América del Norte, y más recientemente en América Latina ${ }^{(3,4)}$. Una experiencia exitosa de Crowdfunding es el caso de Michael Pollastri de la Universidad North Eastern, que logró recaudar 25000 dólares para investigar enfermedades tropicales desatendidas. Como otro ejemplo tenemos a David Hawkes, del Instituto de Neurociencia y Salud Mental Florey, que recaudó 12000 dólares para su investigación en vectores virales para tratar desórdenes neurológicos ${ }^{(5)}$. Es lógico pensar que esta lista se ha incrementado.

Dado el crecimiento masivo de las redes sociales, se proyecta el incremento de este tipo de financiamiento. Actualmente, se cuenta con más de 500 sitios de crowdfunding a nivel mundial y se estiman 5,1 billones de dólares recaudados solo en el $2013^{(5)}$. En el Perú, esta alternativa de financiamiento puede contribuir a incrementar los proyectos de CyT, sobre todo en temas prioritarios de salud que afectan a nuestra sociedad; comenzando a generar oportunidades donde los investigadores jóvenes inicien sus temáticas libres de restricciones en sus ideas, pero con una supervisión del Estado. En ese sentido, sugerimos que se inicie la discusión sobre la aplicabilidad, regulación y reglamentación del crowfunding para maximizar su uso, manteniendo los estándares de calidad y rigurosidad científica en el Perú. 